Quim. Nova, Vol. 36, No. 1, 34-39, 2013

\title{
STABILITY-INDICATING COMPARATIVE METHODS USING MEKC AND LC FOR DETERMINATION OF OLMESARTAN MEDOXOMIL
}

\author{
Lisiane Bajerski*, Clésio S. Paim, Andrea G. Pereira, Carolina L. Dias, Rocheli C. Rossi, Vítor Todeschini, Martin Steppe, \\ Ana Maria Bergold e Pedro E. Fröehlich \\ Faculdade de Farmácia, Universidade Federal do Rio Grande do Sul, Av. Ipiranga, 2752, 90610-000 Porto Alegre - RS, Brasil
}

Recebido em 24/2/12; aceito em 25/7/12; publicado na web em 11/12/12

\begin{abstract}
A stability-indicating method using MEKC was validated for the analysis of olmesartan medoxomil in tablets. Successful separation was achieved using a fused silica capillary (40 cm x $50 \mu \mathrm{m}$ i.d.); background electrolyte consisted of a combination of $10 \mathrm{mmol}$ $\mathrm{L}^{-1}$ borate buffer and $5 \mathrm{mmol} \mathrm{L}^{-1}$ anionic detergent sodium dodecyl sulfate $(95: 5 ; \mathrm{v} / \mathrm{v}) \mathrm{pH} 6.5$; hydrodynamic mode at $50 \mathrm{mBar}$ for $5 \mathrm{~s} ; 25 \mathrm{kV}$ separation voltage at $25^{\circ} \mathrm{C}$; and column temperature $25^{\circ} \mathrm{C}$ with detection at $257 \mathrm{~nm}$. The proposed method, validated following ICH guidelines, was applied to the determination of this antihypertensive with good results compared with an LC method.
\end{abstract}

Keywords: olmesartan medoxomil; MEKC, LC.

\section{INTRODUCTION}

Olmesartan medoxomil (OLM, Figure 1a) is a prodrug that is rapidly and completely de-esterified to the active metabolite olmesartan (OL, Figure 1b) by both arylesterase and albumin during gastrointestinal absorption. ${ }^{1,2}$ It is a selective angiotensin II receptor blocker approved by the US Food and Drug Administration (FDA) in 2002 for the treatment of hypertension, used either alone or in combination with other drugs. OLM is also reported to be effective in animal models of atherosclerosis, liver disorders, and diabetic nephropathy. ${ }^{3}$ This drug, practically insoluble in water and slightly soluble in methanol, is considered a weak basic compound ( $\mathrm{pKa}=$ 4.3), and is chemically known as 5-methyl-(2-oxo-1,3-dioxol-4-yl) methyl-4-(1-hydroxy-1-methylethyl)-2-propyl-1-[2'(1H)-tetrazol5yl)1,1'biphenyl(-4-yl)methyl]-1H-imidazole-5-carboxylate]. ${ }^{4}$

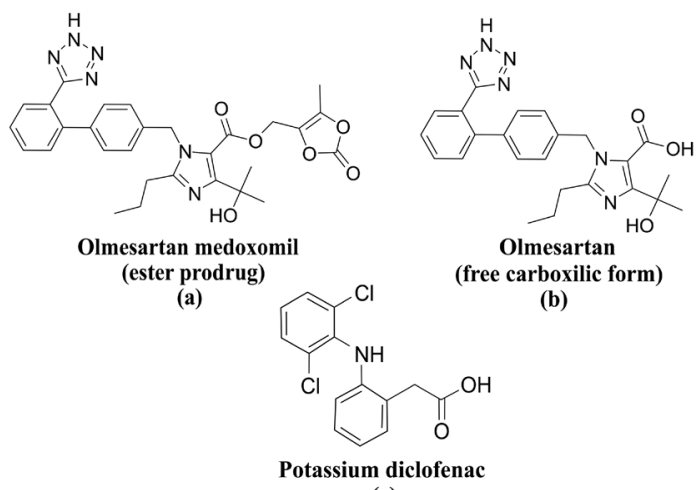

(c)

Figure 1. Chemical structures of olmesartan medoxomil (a), olmesartan (b), and potassium diclofenac (c)

An official technique for OLM quantification in solid dosage forms has not yet been described in the literature. However, methods for determination of this drug isolated in biological fluids (plasma and urine), such as LC coupled with fluorescence and tandem mass spectrometry, ${ }^{2,5-7}$ or combined with other drugs ${ }^{8,9}$ have been reported. Different methods using LC for determination of this antihypertensive

\footnotetext{
*e-mail: lisianebajerski@yahoo.com.br
}

to indicate OLM stability have been reported, ${ }^{10-13}$ but CE (Capillary Electrophoresis) has not been previously used for this purpose. CE has many advantages over LC with respect to separation efficiency, consumption of reagents and samples, analysis time and simplicity of instrumentation. ${ }^{14,15}$ Nevertheless, LC remains the predominant technique in pharmaceutical analysis, but extensive use of CE will generate complementary and alternative methods. On the other hand, the main component and structurally related degradants and impurities in pharmaceutical formulations have similar chemical properties and thus make resolution difficult. However, the greater separation efficiency of CE renders this type of pharmaceutical analysis possible. ${ }^{16}$

$\mathrm{CE}$ is actually a family of techniques with distinct applicability for the separation of compounds of different chemical character, size, and structural features. In micellar electrokinetic chromatography (MEKC), largely used in the analysis of neutral pharmaceuticals, a surfactant is added to the running buffer in a concentration higher than its critical micelle concentration, generating a pseudo stationary phase, in which solute partition takes place. ${ }^{17}$

Currently, there are published methods using CE for the determination of OLM in coated tablets, ${ }^{18}$ its degradation kinetic,,${ }^{19}$ and combined with other drugs, ${ }^{20,21}$ but no methods are available using MEKC. Thus, the goal of this study was to develop and validate a stability-indicating method using MEKC for the determination of this drug in solid pharmaceutical dosage forms, according to the current International Conference on Harmonization (ICH) guidelines, ${ }^{22,23}$ performing a comparison with the previously validated LC method, thereby contributing to the development of new alternatives techniques for the quality control of pharmaceutical formulations.

\section{EXPERIMENTAL}

\section{Chemical and reagents}

The OLM reference substance (RS) was supplied by Sequoia Research Products (Oxford, UK), and potassium diclofenac internal standard (DICL, IS) was purchased from Fracionata (São Paulo, Brazil). One batch of Benicar ${ }^{\circledR}$ (Sankyo Pharma, Brazil) tablets, containing $20 \mathrm{mg}$ of OLM per dose was obtained from commercial sources within their valid shelf life. The excipients contained in the dosage form (cellulose microcrystalline, low substitution hyprolose, 
lactose monohydrate, hyprolose, magnesium stearate, talc, titanium dioxide, hypromelose) were all of pharmaceutical grade and acquired from different distributors.

Both sodium dodecyl sulfate (SDS) and analytical grade boric acid were acquired from Synth (São Paulo, Brazil). Purified water was obtained using a Milli-Q Plus ${ }^{\circledR}$ (Millipore, Bedford, USA). All other reagents and chemicals used were of pharmaceutical or special analytical grade.

\section{Instrumentation}

MEKC experiments were performed on an Agilent 3D CE apparatus (Agilent Technologies, Waldbronn, Germany) equipped with an autosampler, photodiode array (PDA) detector, temperature control system $\left(4-60{ }^{\circ} \mathrm{C}\right)$, and power supply able to deliver up to $30 \mathrm{kV}$. Separation was carried out using a conventional fused silica capillary (40 $\mathrm{cm} \times 50 \mu \mathrm{m}$ i.d.) (Agilent Technologies, Waldbronn, Germany) with a detector window $100 \times 800 \mu \mathrm{m}$, thermostated at $25{ }^{\circ} \mathrm{C}$, and detection at $257 \mathrm{~nm}$. At the beginning of each working day, the capillary was conditioned by rinsing with $0.1 \mathrm{M}$ sodium hydroxide for $30 \mathrm{~min}$, water for $15 \mathrm{~min}$, and finally with the buffer solution for $15 \mathrm{~min}$. To achieve high migration time reproducibility between injections, the capillary was conditioned with $0.1 \mathrm{M}$ sodium hydroxide (3 min), water (1 min), and a running BGE solution (3 min). Samples were injected using the hydrodynamic injection for $5 \mathrm{~s}$ at $50 \mathrm{mBar}$ and a constant voltage of $25 \mathrm{kV}$ was applied during the analysis. Since electrolysis can change the electro-osmotic flux (EOF) and affect migration time, efficiency and selectivity, after every three injections the running electrolyte solution was replaced by a fresh solution. CE ChemStation software (version A 09.01) was used for instrumentation control, data acquisition, and analysis. The Ultrabasic potentiometer (Denver Instrument, São Paulo, Brazil) was used to determine the $\mathrm{pH}$ of all solutions and a $0.22 \mu \mathrm{m}$ membrane filter Millipore (Belford, USA) was used to filter the solutions.

LC was carried out on a Shimadzu LC system (Kyoto, Japan) which consisted of a LC-10AD pump, SPD-M10ADVP photodiode array (PDA) detector, SLA-10ADVP system controller, DGU-14A degasser and an Rheodyne ${ }^{\circledR} 7725$ i manual injector with a $20 \mu \mathrm{L}$ loop. Data were acquired and processed using CLASS-VP software (version 6.1). Elution was carried out on a Phenomenex ${ }^{\circledR}$ RP-18 column $(250$ x $4.6 \mathrm{~mm}$ i.d., particle size $5 \mu \mathrm{m})$ with a guard column $(4 \times 3 \mathrm{~mm}$ i.d.) packed with the same material, mobile phase consisted of wate r:triethylamine:acetonitrile (40:0.3:60 $\mathrm{v} / \mathrm{v} / \mathrm{v}, \mathrm{pH}$ adjusted to 6.3 with phosphoric acid), flow rate of $1.2 \mathrm{~mL} \mathrm{~min}^{-1}$, detection at $257 \mathrm{~nm}$ at room temperature, and an injection volume of $20 \mu \mathrm{L}$.

Photodegradation was carried out in a photostability UV chamber $(1.0 \times 0.17 \times 0.17 \mathrm{~m})$ with mirrors, equipped with a UV-A lamp (Orion $^{\circledR}, 352$ nm, $30 \mathrm{~W}, 130 \mathrm{~V}$ ) while UV cuvettes (Ultra Vette ${ }^{\circledR}$, São Paulo, Brazil) were used as containers for samples. A dry air oven (Biomatic ${ }^{\circledR}$, Porto Alegre, Brazil) was used for thermal stability studies.

\section{Preparation of standard solutions and pharmaceutical samples}

Stock solution of OLM RS (1000 $\left.\mu \mathrm{g} \mathrm{mL} \mathrm{m}^{-1}\right)$ was prepared by accurately weighing $10 \mathrm{mg}$ of the drug and dissolving it in acetonitrile.

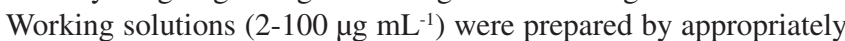
diluting the stock solutions with acetonitrile. DICL IS solution, previously prepared in methanol, was added to each flask at a constant aliquot of $50 \mu \mathrm{g} \mathrm{mL}^{-1}$. The stock solution of OLM RS was prepared daily for each analysis, due to instability, and the DICL IS was stored at $8 \pm 2{ }^{\circ} \mathrm{C}$, protected from light, and diluted daily to an appropriate concentration with methanol.
Twenty units of tablets were weighed and average weight calculated. The samples were crushed to a fine powder and an amount of the resultant material, equivalent to $10 \mathrm{mg}$ OLM from the pharmaceutical formulation, was transferred to a $50 \mathrm{~mL}$ volumetric flask. Subsequently, the volume was adjusted with acetonitrile and sonicated for $15 \mathrm{~min}$ and filtered through quantitative filter paper (Schleicher $\&$ Schuell, Dassel, Germany). Aliquots of this solution were diluted to give a final concentration of $50 \mu \mathrm{g} \mathrm{mL}^{-1}$. The solutions were then filtered through a $0.22 \mu \mathrm{m}$ membrane filter (Millipore ${ }^{\circledR}$ ) prior to analysis. For quantitative purposes, DICL was chosen as the IS.

\section{Preparation of background electrolyte solution}

The optimized background electrolyte (BGE) aqueous solution was prepared by separate weighing of boric acid and SDS quantities, equivalent to $100 \mathrm{mmol} \mathrm{L}^{-1}$, respectively. Posterior dilutions were done with boric acid solution to obtain $10 \mathrm{mmol} \mathrm{L}^{-1}$ final concentration. The SDS solution was also diluted to $5 \mathrm{mmol} \mathrm{L}^{-1}$, using $10 \mathrm{mmol}$ $\mathrm{L}^{-1}$ of previously prepared boric acid solution as the diluent. The $\mathrm{pH}$ was adjusted to 6.5 by adding sodium hydroxide $0.1 \mathrm{M}$, and the volume completed to $50 \mathrm{~mL}$ with the same diluent. The solution was prepared daily and filtered.

\section{Method validation}

This method was validated using samples of pharmaceutical formulation of OLM with the label claim of $20 \mathrm{mg}$ by determinations of the following parameters: specificity, linearity, LOD, LOQ, precision, accuracy, robustness, stability, and system suitability test, following $\mathrm{ICH}$ guidelines. ${ }^{22,23}$

\section{Forced degradation studies}

The stability-indicating capability of the method was determined by subjecting an OLM RS solution $\left(1000 \mu \mathrm{g} \mathrm{mL}^{-1}\right)$ to accelerated degradation by acidic, basic, oxidative, thermal, and photolytic conditions to evaluate interference in the quantitation of the drug.

Solutions for acid and basic hydrolysis studies of the drug substance were prepared in a mixture of $0.01 \mathrm{M} \mathrm{HCl}$ - acetonitrile $(70: 30 \mathrm{v} / \mathrm{v})$ and $0.01 \mathrm{M} \mathrm{NaOH}$ - acetonitrile $(70: 30 v / v)$, respectively. Both solutions were protected from light and stored at room temperature $(23 \pm$ $1{ }^{\circ} \mathrm{C}$ ), for analysis after $24 \mathrm{~h}$. The oxidative degradation was induced by storing the solution in a mixture of $3 \% \mathrm{H}_{2} \mathrm{O}_{2}$ - acetonitrile (70:30 $v / v)$, at room temperature $\left(23 \pm 1{ }^{\circ} \mathrm{C}\right)$ for $24 \mathrm{~h}$, protected from light. For thermal degradation, the reference substance in powder form (dry heat) and in solution (moist heat) was exposed at $80^{\circ} \mathrm{C}$ in an oven, for 24 and $1 \mathrm{~h}$, respectively. Photodegradation was induced by placing the reference substance sample solid and solution in a glass dish and quartz cuvettes, respectively, which were then placed in a light chamber, and exposed to UV-A radiation $(352 \mathrm{~nm})$ for $48 \mathrm{~h}$, at room temperature. Control samples were protected from light with aluminum foil and also placed in the light chamber and exposed concurrently.

Following the degradation period, all samples were prepared for analysis as previously described above and the specificity of the method was established by determining the peak purity of OLM in the degraded samples using a PDA detector.

\section{Specificity}

The method specificity was also investigated by observing all interferences encountered from OLM tablets excipients, as described in the Experimental section. Excipient concentration in this dosage form was based on the literature ${ }^{24,25}$ and calculated in relation to medium 
weight. The electropherograms of excipient placebo solution (without drugs), OLM RS and DICL IS solutions were compared to verify the probable interference of the excipients on OLM quantitation.

\section{Linearity and limits of detection (LOD) and quantitation (LOQ)}

Linearity was studied by injecting solutions in the concentration range of 2-100 $\mu \mathrm{g} \mathrm{mL}^{-1}$ of OLM, and a fixed aliquot of an IS. RS solutions were prepared at eight concentrations $(2,5,10,25,50,75,100 \mu \mathrm{g}$ $\mathrm{mL}^{-1}$ ) and injected in triplicate every day, for 3 consecutive days. The ratio of peak area values of OLM RS and DICL IS was computed and analyzed using linear least-squares regression parameters (correlation coefficient, slope, intercept). The LOD and LOQ values were mathematically determined through calibration curves. The aforementioned factors ( 3.3 and 10) were multiplied by the ratio of the residual standard deviation and the slope, according to guidelines. ${ }^{22}$

\section{Precision}

The intra-day precision was analyzed through the preparation of 6 samples containing $50 \mu \mathrm{g} \mathrm{mL}^{-1}$ of OLM tablets and DICL IS, injected in triplicate, on the same day $(n=6)$. Inter-day precision was tested by repeating the same procedure on 3 different days ( $n$ $=18$ ) and comparing the results for the different days. The data on precision of tablets were expressed as percentage relative standard deviation (RSD\%).

\section{Accuracy}

The accuracy of the method was evaluated by preparing synthetic excipients representative of OLM tablets, and spiking three samples with OLM RS at the concentration levels corresponding to 40 (low), 50 (medium) and $60 \mu \mathrm{g} \mathrm{mL}^{-1}$ (high) (i.e. equivalent to 80, 100, and $120 \%$ ), and a fixed aliquot of a DICL IS. The OLM was extracted from the excipients and determined. Each solution was prepared in triplicate and injected 3 times. The concentrations and recoveries were calculated against the added concentration.

\section{Stability of solutions}

Solutions of OLM RS, DICL IS, and OLM tablets were prepared as described in the Preparation section of standard solutions and pharmaceutical samples. The stability of these solutions was checked after 24 and $48 \mathrm{~h}$ and compared against freshly prepared solutions. The initial peak area was considered $100 \%$ and the recoveries on subsequent days were evaluated.

\section{Robustness}

Robustness of the proposed method was examined by evaluating the influence of small variations of the most important procedure variables such as buffer concentration ( 9.5 and $\left.10.5 \mathrm{mmol} \mathrm{L}^{-1}\right)$, SDS concentration (4.5 and $5.5 \mathrm{mmol} \mathrm{L}^{-1}$ ), BGE pH solution (6.2 and 6.7), voltage $(28 \mathrm{KV})$, and temperature system $\left(23\right.$ and $\left.27^{\circ} \mathrm{C}\right)$. Analyses were carried out with OLM RS and DICL IS solutions at $50 \mu \mathrm{g} \mathrm{mL} \mathrm{mL}^{-1}$, in triplicate. Only one parameter in the experiments was changed at a time, and the effects were studied based on RSD (\%) values obtained among the parameters analyzed.

\section{System suitability test}

The system suitability test is an integral part of the analytical method and ascertains the suitability and effectiveness of the operating system. It was also carried out to evaluate the resolution and reproducibility of the system for the analysis to be performed, using 5 replicate injections of OLM RS and DICL IS solution containing $50 \mu \mathrm{g} \mathrm{mL} \mathrm{L}^{-1}$.

\section{RESULTS AND DISCUSSION}

To obtain the optimum capillary electrophoresis conditions, some electrolyte solutions containing sodium phosphate, potassium phosphate, sodium tetraborate, and boric acid, respectively, were investigated adding the surfactant SDS, in the $\mathrm{pH}$ range 6.0-7.5. The best peak symmetry and resolution between the peaks were obtained using borate solution, at $\mathrm{pH} 6.5$.

The effect of BGE concentration was studied in the range from 5 to $20 \mathrm{mmol} \mathrm{L}^{-1}$, with constant $5 \mathrm{mmol} \mathrm{L}^{-1}$ SDS concentration, at $\mathrm{pH}$ 6.5. Since the peak symmetry and the migration time increased with the increase of borate buffer concentration, the $10 \mathrm{mmol} \mathrm{L}^{-1}$ borate solution was selected due to the low current and suitable peak parameters generated.

The influence of the SDS was also investigated in the concentration range from 5 to $50 \mathrm{mmol} \mathrm{L}^{-1}$, with constant $10 \mathrm{mmol} \mathrm{L}^{-1}$ borate buffer concentration, at $\mathrm{pH}$ 6.5. The OLM migration time and peak symmetry increased with increase in the concentrations, achieving better efficiency combined with shorter analysis time with $5 \mathrm{mmol} \mathrm{L}^{-1}$ SDS.

The BGE pH solution containing $10 \mathrm{mmol} \mathrm{L}^{-1}$ boric acid and 5 mmol L ${ }^{-1}$ SDS was evaluated in the 6.0-7.5 range, and the $\mathrm{pH} 6.5$ was selected with peak symmetry (around 1.84), since lower pHs resulted in an increase in migration time and peak width. The best parameters such as peak symmetry (around 1.84) and resolution were obtained with BGE solution containing $10 \mathrm{mmoL}^{-1}$ boric acid and $5 \mathrm{mmol} \mathrm{L}^{-1}$ SDS $(95: 5, v / v)$, at $\mathrm{pH} 6.5$. $\mathrm{pH}$ values lower than 6.5 resulted in a decrease in migration time and resolution between peaks, whereas $\mathrm{pH}$ higher than 6.5 led to an increase in migration time and peak width.

The effect of the voltage was investigated from 20 to $30 \mathrm{kV}$, and showed shorter analysis time along with better separation efficiencies at values up to $25 \mathrm{kV}$ potential, which also showed best peak parameters and acceptable current (around $6.0 \mu \mathrm{A}$ ), without excessive Joule heating.

The capillary temperature was investigated within the 20 to $30^{\circ} \mathrm{C}$ range, and a temperature of $25^{\circ} \mathrm{C}$ was chosen due to the short analysis time. The sample solutions were hydrodynamically injected at 50 $\mathrm{mBar}$ changing the injection time from between 3 to $8 \mathrm{~s}$, showing increased peak width and deformed shape after $5 \mathrm{~s}$, thus the injection time selected was $5 \mathrm{~s}$.

As reported, the MEKC method parameters were optimized to obtain the best peak area, resolution and symmetry, combined with short migration time, being achieved using a $10 \mathrm{mmol} \mathrm{L}^{-1}$ solution of borate buffer and $5 \mathrm{mmol} \mathrm{L}^{-1} \mathrm{SDS}$ at $\mathrm{pH} 6.5$, with detection at 257 $\mathrm{nm}$. The use of low concentrations levels of BGE and SDS contribute to raising the capillary and the equipment validity, due to the lower current generated. ${ }^{26}$

The use of an IS is recommended to compensate injection errors and minor fluctuations of the migration time thereby improving the quantitative analysis. Thus, several drugs including nimesulide, losartan, hydrochlorothiazide, and salicylic acid were tested. However, only DICL (Figure 1c), a non-steroidal anti-inflammatory drug, proved to be a suitable candidate with well-resolved peak in relation to OLM.

The electropherogram of OLM RS and DICL IS with migration times of 2.2 and $2.5 \mathrm{~min}$, respectively, is shown in Figure 2a.

A stability-indicating method is defined as an analytical technique that accurately quantifies the active ingredients without interference 

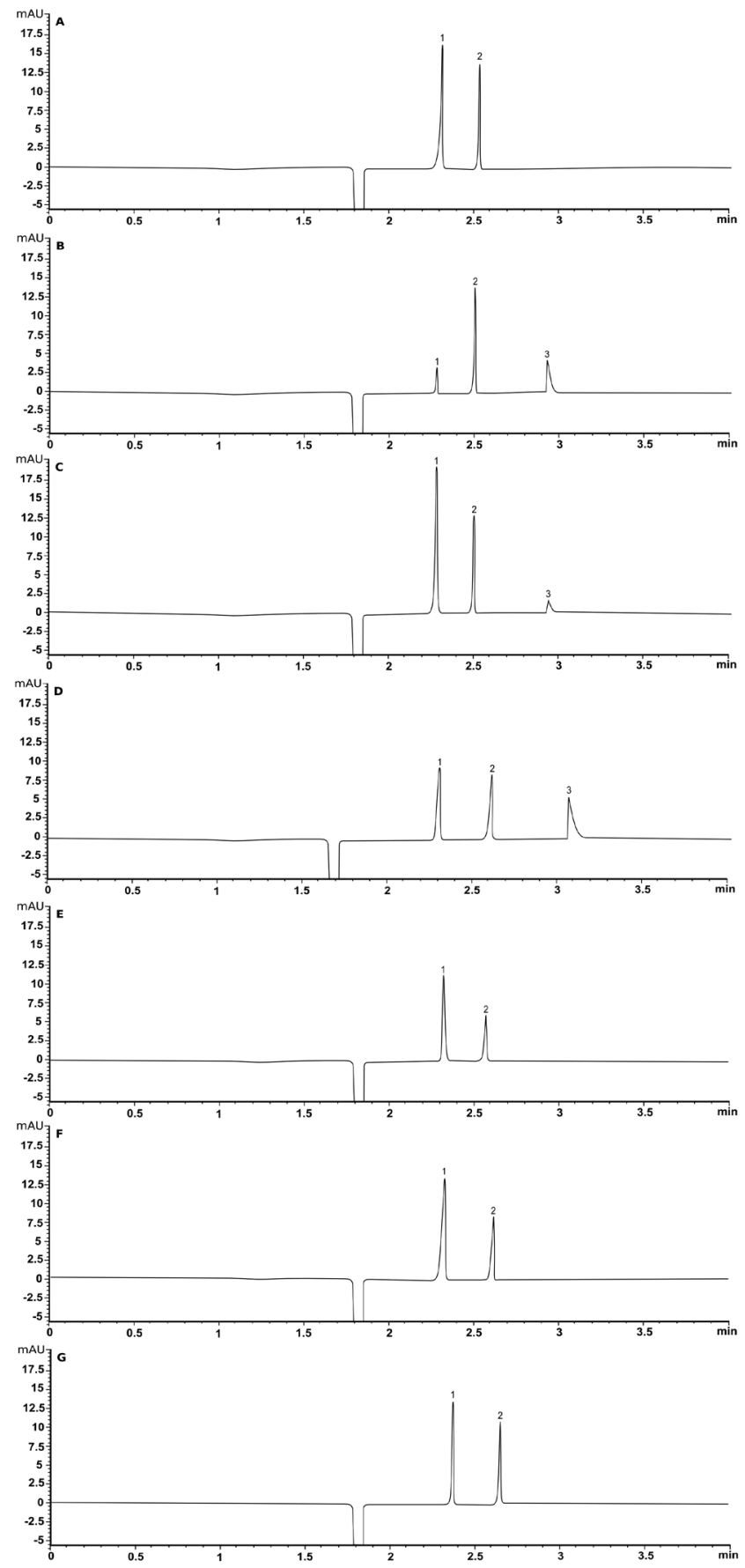

Figure 2. Typical MEKC electropherograms of: (A) OLM RS solution (peak: 1) and DICL IS (peak: 2); (B) acid hydrolysis 24 h (peak 3: degradation form); (C) alkaline hydrolysis 24 h (peak 3: degradation form); (D) oxidative stress 24 h (peak 3: degradation form); (E) dry heat stress $24 h ;(F)$ moist heat stress $1 \mathrm{~h}$; $(\mathrm{G})$ photolytic stress $48 \mathrm{~h}$. Eletrophoretic conditions: $10 \mathrm{mmol} \mathrm{L}^{-1}$ boric acid: 5 mmol $L^{-1} S D S(95: 5 ; v / v) p H 6.5$; fused silica capillary $(40.0 \mathrm{~cm} \times$ $50 \mu \mathrm{m}$ i.d.); hydrodynamic injection time of $5 \mathrm{~s}$ at pressure $0.5 \mathrm{psi}$; separation voltage $25 \mathrm{kV}$; and column temperature $25^{\circ} \mathrm{C}$ with detection at $257 \mathrm{~nm}$

from degradation products, process impurities, excipients, or other potential impurities. ${ }^{27}$ Thus, the evaluation of stability-indicating capability and selectivity of the proposed method was done by submitting the OLM RS to several forced degradation conditions.

The results proved that when this drug was submitted to acidic, basic, and oxidative conditions, the electropherograms showed a significant OLM RS area decrease equivalent to 63.5, 57.0, and
$42.1 \%$, respectively, and an additional peak at $2.9 \mathrm{~min}$, in all situations (Figures 2b, c, and d). This drug was considered to be stable when exposed to dry heat in solid state (Figure 2e). However, when exposed to moist heat in solution (Figure $2 \mathrm{f}$ ) and photolytic conditions, there was significant degradation, albeit lower in comparison with the conditions of hydrolysis and oxidation. In both cases, there was an area decrease, correspondingly to 8.2 and $9.5 \%$, but no additional peak was observed.

The peak purity indexes confirmed that there was no interference from any other substance on the OLM RS (2.2 min), DICL IS (2.5 $\mathrm{min}$ ), and major degradation product (2.9 $\mathrm{min}$ ) migration times, showing that these were $99.9 \%$ pure under all circumstances. Thus, it was confirmed that there was no interference from any other substance on the migration time of the drug. In addition, it was verified that the OLM peak presented appropriate resolution and selectivity in relation to the degradation product formed.

In relation to diode-array spectrum (200-400 nm) analysis, the degradation product, obtained under all stress conditions, had the same spectrum and migration time. Thus, since the OLM is the ester prodrug of OL, it is reasonable to assume that the degradation product is OL. This supposition can be confirmed through studies conducted by Murakami et al.. ${ }^{10}$ However, OL reference substance should be used to confirm this assumption.

According to results, the proposed method can be considered stability-indicating, since it was successful not only for separation, but also for evaluating, qualitatively and quantitatively, OLM in the presence of the degradation product formed. Furthermore, the degradation studies showed that this ester prodrug is susceptible to hydrolysis and oxidation, and therefore care must be exercised when manipulating the drug.

The specificity of the method for the drug was established through determination of the purity peak of the analyte and the IS in the working standard solution using a PDA detector. No interference from formulation excipients was found, showing that the peaks were free from any co-eluting peak, demonstrating that the proposed method is specific for the analysis of OLM.

The statistical parameters of the analytical curve and estimates of LOD and LOQ for both methods are given in Table 1. The calibration curves proved to be linear over the $2-100 \mu \mathrm{g} \mathrm{mL}^{-1}$ range. Linear regression of concentration versus peak area ratio plots resulted in an average of coefficient correlation $(r)$ greater than 0.999 . The validity of the assay was verified by means of analysis of variance (ANOVA), which demonstrated that the regression equation was linear $\left(F_{\text {calculated }}\right.$ $=1.9 \cdot 10^{3}>F_{\text {critical }}=4.6 ; \alpha=0.05$ ) with no deviation from linearity $\left(F_{\text {calculated }}=9.0 \cdot 10^{-2}<F_{\text {critical }}=2.9 ; \alpha=0.05\right)$.

The LOD and LOQ were estimated to be 1.3 and $4.0 \mu \mathrm{g} \mathrm{mL}^{-1}$, respectively, indicating suitable sensitivity of the method.

The results of precision are summarized in Table 2 . The low RSD $(\%)$ obtained for the intra-day $(<2.0 \%)$ and inter-day precision $(1.7 \%)$ for tablets, confirmed good precision of the MEKC method.

The accuracy results for tablets showed good recovery and are listed in Table 2. Accuracy OLM results, at three levels by the standard addition technique, ranged from 98.4 to $101.5 \%$, with RSD lower than $2.0 \%$. These values confirmed good accuracy of the proposed method.

The stability of OLM RS, DICL IS, and OLM tablets solution in acetonitrile was determined by monitoring the peak area ratio of these solutions over a period of 2 days. The results showed that the peak area RSD (\%) was lower than $2.0 \%$, and no significant degradation was observed within $24 \mathrm{~h}$, at both temperatures tested. After $48 \mathrm{~h}$, an extra peak was observed.

The results of variables over the experimental range evaluated were within the acceptable deviation (RSD $<2.0 \%$ ). There were non-significant changes in migration time and peak area ratios, as 
Table 1. Validation parameters evaluated for MEKC and LC methods

\begin{tabular}{|c|c|c|}
\hline Validation parameter & MEKC method & LC method \\
\hline \multicolumn{3}{|l|}{ Linearity } \\
\hline Range $\left(\mu \mathrm{g} \mathrm{mL}^{-1}\right)$ & $2-100$ & $10-30$ \\
\hline Intercept & 0.0119 & 50715 \\
\hline Slope & 0.0064 & 11444 \\
\hline Correlation coefficient & 0.999 & 0.999 \\
\hline $\mathrm{LOD}\left(\mu \mathrm{g} \mathrm{mL} \mathrm{L}^{-1}\right)$ & 1.3 & 0.6 \\
\hline $\mathrm{LOQ}\left(\mu \mathrm{g} \mathrm{mL}^{-1}\right)$ & 4.0 & 2.0 \\
\hline \multicolumn{3}{|l|}{ Precision } \\
\hline Intra-day $\%(n=6)$ & 100.9 & 99.4 \\
\hline $\operatorname{RSD} \%^{\mathrm{a}}$ & 1.9 & 1.4 \\
\hline Inter-day $\%(n=18)$ & 101.0 & 99.4 \\
\hline $\operatorname{RSD} \%^{\mathrm{a}}$ & 1.6 & 1.4 \\
\hline \multicolumn{3}{|l|}{ Accuracy } \\
\hline Mean recovery $\%(n=9)$ & 100.0 & 100.2 \\
\hline $\operatorname{RSD} \%^{\mathrm{a}}$ & 1.4 & 0.9 \\
\hline
\end{tabular}

${ }^{a}$ Relative standard deviation.

Table 2. MEKC conditions and investigated range during robustness testing

\begin{tabular}{lcc}
\hline Variable & Range investigated & OLM $(\%)^{\mathrm{a}}$ \\
\hline Buffer $\mathrm{pH}$ & 6.3 & 99.9 \\
& 6.7 & 97.2 \\
Buffer concentration (mmol) & 9.5 & 97.6 \\
& 10.5 & 97.8 \\
SDS concentration (mmol) & 4.5 & 100.8 \\
& 5.5 & 99.0 \\
Temperature $\left({ }^{\circ} \mathrm{C}\right)$ & 23 & 98.9 \\
& 27 & 100.3 \\
Voltage $(\mathrm{kV})$ & 28 & 99.4 \\
\hline RSD $(\%)^{\mathrm{b}}$ & - & 1.3 \\
\hline
\end{tabular}

${ }^{\mathrm{a}}$ Each value is the mean of three analysis. ${ }^{\mathrm{b}}$ Relative standard deviation.
Table 3. Results of the system suitability test

\begin{tabular}{lcc}
\hline Parameter & OLM $(\mathrm{RS})^{\mathrm{a}}$ & DICL $(\mathrm{IS})^{\mathrm{a}}$ \\
\hline Theoretical plates & 88014 & - \\
Tailing factor & 1.8 & 1.1 \\
Resolution & 10.5 & - \\
Migration time (min) & $2.2\left(\mathrm{RSD}^{\mathrm{b}}=1.8 \%\right)$ & $2.5\left(\mathrm{RSD}^{\mathrm{b}}=1.5 \%\right)$ \\
$\begin{array}{l}\text { The peak area ratio of } \\
\text { OLM to DICL (Injection } \\
\text { repeatability) }\end{array}$ & $1.6\left(\mathrm{RSD}^{\mathrm{b}}=0.9 \%\right)$ & \\
& \\
${ }^{\mathrm{a}}$ Mean of five replicates ${ }^{\mathrm{b}}$ Relative standard deviation.
\end{tabular}

${ }^{a}$ Mean of five replicates. ${ }^{b}$ Relative standard deviation.

well as in the electropherogram pattern compared to the optimized conditions, indicating that the proposed method is robust under the conditions tested (Table 2).

The results obtained on the system suitability test (Table 3) were satisfactory in accordance with the literature ${ }^{28}$ and ensure that the MEKC system generates reliable results. The parameters tested were within the acceptable range (RSD $<2.0 \%$ ), indicating that the method is suitable for the analysis intended.

The MEKC method validated in this paper was applied in parallel with the LC method developed previously by our group. The results obtained for both these methods were compared statistically by ANOVA, using the $F$-test (Table 4 ), and detected no significant difference between the experimental values obtained for coated tablets by MEKC and by LC methods. The calculated $F$-value for tablets $\left(F_{\text {calculated }}=2.1\right)$ was found to be less than the critical $F$-value $\left(F_{\text {critical }}\right.$ $=7.7)$, at a $5 \%$ level of significance. This fact indicates that MEKC can be used as an alternative method to LC for quantifying OLM tablets with a high degree of reliability.

\section{CONCLUSION}

The proposed method using MEKC can be considered stability-indicating, due to its ability to detect OLM in the presence of its degradation product, yielding results comparable to LC. Therefore, the proposed method was successfully applied as an alternative tool for the quantitative analysis of OLM in a pharmaceutical dosage form, representing an improvement for quality control, and also contributing to assure therapeutic efficacy of the drug.

Table 4. Comparison between using MEKC and LC in an assay of pharmaceutical formulations

\begin{tabular}{|c|c|c|c|c|c|c|c|}
\hline \multirow{3}{*}{ Sample } & \multirow{3}{*}{$\begin{array}{l}\text { Theoretical } \\
\text { amount/mg per } \\
\text { tablets }\end{array}$} & \multicolumn{6}{|c|}{ Experimental amount } \\
\hline & & \multicolumn{3}{|c|}{$\mathrm{MEKC}^{\mathrm{a}}$} & \multicolumn{3}{|c|}{$\mathrm{LC}^{\mathrm{a}}$} \\
\hline & & $\mathrm{mg}$ & $\%$ & $\mathrm{RSD}^{\mathrm{b}}$ & $\mathrm{mg}$ & $\%$ & $\mathrm{RSD} \%^{\mathrm{b}}$ \\
\hline 1 & 20 & 20.2 & 101.2 & 0.6 & 19.9 & 99.4 & 1.4 \\
\hline 2 & 20 & 20.1 & 100.6 & 1.9 & 19.7 & 98.8 & 1.8 \\
\hline 3 & 20 & 20.4 & 101.9 & 1.4 & 20.3 & 101.5 & 1.8 \\
\hline
\end{tabular}

${ }^{a}$ Each value is the mean of 6 analyses. ${ }^{b}$ Relative standard deviation.

\section{ACKNOWLEDGMENT}

The authors wish to thank CNPq (Conselho Nacional de Desenvolvimento Científico e Tecnológico) for the support.

\section{REFERENCES}

1. Norwood, D.; Branch, E.; Smith, B.; Honeywell, M.; P T 2002, 27, 611.

2. Laeis, P.; Puchler, K.; Kirch, W.; J. Hypertens. Suppl. 2001, 19, S21.
3. Sagirli, O.; Onal, A.; Toker, S. E.; Sensoy, D.; Chromatographia 2007, $66,213$.

4. Koike, H.; Konse, T.; Sada, T.; Ikeda, T.; Hyogo, A.; Hinman, D.; Saito, H.; Annual Report Sankyo Research Laboratories, 2003.

5. Lui, D.; Hu, P.; Matsushima, N.; Li, X.; Li, L.; Jiang, J.; J. Chromatogr., B: Anal. Technol. Biomed. Life Sci. 2007, 856, 190.

6. Nakamura, H.; Inoue, T.; Arakawa, N.; Shimuzi, Y.; Yoshigae, Y.; Fujimori, I.; Shimakawa, E.; Toyoshi, T.; Yokoyama, T.; Eur. J Pharmacol. 2005, 512, 239. 
7. Vaidya, V. V.; Roy, S. M. N.; Yetal, S. M.; Joshi, S. S.; Parekh, S. A.; Chromatographia 2008, 67, 147.

8. Sagirli, O.; Onal, A.; Toker, S. E.; Sensoy, D.; Chromatographia 2007, 66, 213.

9. Najma, S.; Saeed, A. M.; Shahid, A. S.; Shahnawaz, S.; Chin. J. Chromatogr. 2008, 26, 544.

10. Murakami, T.; Konno, H.; Fukutsu, N.; Onodera, M.; Kawasaki, T.; Kusu, F.; J. Pharm. Biomed. Anal. 2008, 47, 553.

11. Rane, V. P.; Patil, K. R.; Sangshetti, J. N.; Yeole, R. D.; Shinde, D.; Chromatographia 2009, 69, 169.

12 Trivedi, P.; Kartikeyan, C.; Kachave, R.; Bhadane, R.; J. Liquid Chromatogr. Rel. Technol. 2009, 32, 1516.

13. Sharma, N. R.; Pancholi, S. S.; Acta Pharm. 2010, 60, 13.

14. Currell, G.; Analytical instrumentation, performance characteristics and quality, Analytical Techniques in the Sciences, Wiley: New York, 2000.

15. Jager, A. V.; Tavares, M. F. M.; Quim. Nova 2001, 24, 363.

16. Altria, K. D.; Rogan, M. M.; Introduction to Quantitative Applications of Capillary Electrophoresis in Pharmaceutical Analysis, Ed. Beckman: Fullerton, 2006.

17. Altria, K. D.; J. Chromatogr. 1993, 646, 245.

18. Çelebier, M.; Altínoz, S.; Chromatographia 2007, 66, 929.

19. Çelebier, M.; Altínoz, S.; Lat. Am. J. Pharm. 2009, 28, 108.
20. Çelebier, M.; Altínoz, S.; Hacettepe University Journal of the Faculty of Pharmacy 2007, 27, 119.

21. Çelebier, M.; Süslü, I.; Altínoz, S.; Lat. Am. J. Pharm. 2011, 30, 753.

22. ICH; Validation of Analytical Procedures: Text and Methodology $Q 1 A(R 2)$; International Conference on Harmonisation (ICH) of Technical Requirements for Registration of Pharmaceuticals for Human Use, Geneve, 2005.

23. ICH; Validation of Analytical Procedures: Text and Methodology Q2B; International Conference on Harmonisation (ICH) of Technical Requirements for Registration of Pharmaceuticals for Human Use, Geneve, 2005.

24. Bajerski, L.; Rossi, R. C.; Dias, C. L.; Fröehlich, P. E.; Bergold, A. M.; Chromatographia 2008, 68, 991.

25. Rowe, R. C.; Sheskey, P. J.; Welle, P. J.; Handbook of pharmaceutical excipients, Welle: Washington, 2000.

26. Nogueira, D. R.; Sangoi, M. S.; Silva, L. M.; Todeschini, V.; Dalmora, S. L.; J. Sep. Sci. 2008, 31, 3098.

27. Alsante, K. M.; Ando, A.; Brown, R.; Ensing, J.; Hatajik, T. D.; Kong, W.; Tsuda, Y.; Adv. Drug Deliv. Rev. 2007, 59, 29.

28. USP; The United States Pharmacopoeia, $35^{\text {th }}$ ed., United States Pharmacopoeia Convention: Rockville, 2012. 